\title{
O NEXO FEDERAL: a relação entre sistemas partidários e políticas públicas no Brasil e na Argentina ${ }^{1}$
}

\author{
Ximena Simpson*
}

\begin{abstract}
O trabalho ressalta o papel do sistema de partidos no Brasil e na Argentina como elemento central para a compreensão da capacidade de coordenação das relações intergovernamentais (RIGs) e, consequentemente, para a implementação de políticas públicas nacionais. O argumento central é que os níveis de conflitividade das RIGs, ao longo da história, são modelados pelo sistema partidário, com implicações diretas nas políticas públicas. A hipótese é que uma maior nacionalização do sistema partidário resulta em RIGs mais cooperativas, e, consequentemente, maior capacidade de penetração territorial do estado central, com políticas públicas intertemporais. Conclui-se que a dinâmica das RIGs, nos países em questão, alcança resultados contrários: enquanto, na Argentina, parece incentivar uma maior territorializaçao partidária, no Brasil, encaminha-se para a construção de um marco de interação mais cooperativo.
\end{abstract}

Palavras-Chave: Federalismo. Sistema partidário. Políticas públicas. Brasil. Argentina.

\section{INTRODUÇAO}

Os mecanismos de coordenação de interesses entre diferentes níveis de governo autônomo constituem aspectos-chave para se entender a produção de políticas públicas em uma estrutura federativa. Assim sendo, para garantir essa coordenação nas relações intergovernamentais (doravante RIGs), as federações devem, em primeiro lugar, equilibrar as formas de competição existentes, levando em conta que o federalismo é intrinsecamente conflituoso (Abrúcio, 2005). A partir dessa problemática, temos que o impacto do federalismo no funcionamento do Estado vai além das macroestruturas políticas.

O presente trabalho objetiva discutir a relevância analítica do impacto das clivagens federais nas políticas públicas, através do es-

* Universidad Nacional de San Martín. Escuela de Política y Gobierno.

Av. 25 de Mayo 1021. Edifcício de Ciencias Sociales. San

Martín (1650). Argentina. xsimpson@gmail.com

${ }^{1} \mathrm{O}$ presente trabalho é um resultado parcial da pesquisa

"Democracia, Estado y Relaciones Estado-Sociedad en las

Provincias Argentinas", financiado pelo FONCYT (PICT

1712-2014) tudo da dinâmica partidária. ${ }^{2} \mathrm{O}$ argumento central é que os níveis de conflitividade das relações intergovernamentais, ao longo da história, são modelados pelo sistema partidário, com implicações diretas nas políticas públicas. Não é objetivo deste trabalho analisar sua qualidade ou seu conteúdo, nem o nível de pluralismo do sistema político. O objetivo é circunscrito a chamar a atenção para a relevância do sistema partidário como elemento central na compreensão do impacto das clivagens federais no funcionamento do Estado.

A hipótese do presente trabalho é que, em termos de integração do sistema partidário, uma maior nacionalização (Chhibber; Kollman, 2004) se reflete em relações intergovernamentais mais cooperativas e, consequentemente, maior capacidade de penetração territorial do estado central, através de políticas públicas intertemporais. O conceito de nacionalização partidária tem sido utilizado na lite-

${ }^{2}$ Este artigo tem como objetivo central trazer à tona a discussão sobre o impacto das clivagens federais no sistema partidário. Nesse sentido, priorizou-se a construção de um marco teórico que oriente análises comparativas. Uma análise estatística das variáveis abordadas foge ao escopo do presente texto, mas fica como agenda pendente para próxima publicação. 
ratura comparativa para se referir ao grau em que a variação da votação dos partidos entre os diferentes distritos se aproxima ou se distancia da votação nacional (Chhibber; Kollman, 2004; Jones; Mainwaring, 2003). Contudo, como é proposto por Borges (2015) e Melo (2010), em sistemas com múltiplos níveis de governo, os partidos sem condição de apresentar candidatos presidenciais viáveis têm a opção de se especializar nas disputas estaduais. Quanto maior o impacto positivo do desempenho dos partidos nas eleições para governador sobre suas votações na eleição legislativa nacional, tanto maior a possibilidade de sucesso das estratégias de ampliação da base territorial de votação por meio do lançamento de candidaturas ao governo estadual nos vários distritos.

Nesses dois sentidos, argumenta-se que uma maior nacionalização do sistema partidário irá se refletir em relações intergovernamentais mais cooperativas. ${ }^{3}$ Uma maior cooperação está condicionada à adoção de regras que sirvam de parâmetros para o jogo político, porém, ao se tratar de relações políticas, não se pressupõe assepsia ou ausência de interferências na interação entre os atores. Essas regras, no entanto, serão responsáveis pela flexibilidade necessária para dotar o processo político de maior credibilidade pois, além de delimitarem $\approx$ o espaço das crises e as circunscreverem aos . conflitos intrínsecos à Federação, conferem $\dot{8}$ estabilidade suficiente ao sistema para que a instabilidade inerente ao processo político não cause maiores danos (Mora, 2002).

$\mathrm{O}$ artigo faz uma comparação entre os casos do Brasil e da Argentina. Deve-se essa escolha ao fato de tratar-se de duas das mais importantes federações da América Latina. Em termos comparativos, uma primeira aproximação nos permite observar que, apesar de apresentarem estruturas institucionais semelhantes (ambos são federalismos presidencialistas com significativos graus de descentralização política e administrativa), a dinâmica dos pro-

${ }^{3}$ Cabe destacar que o de grau de integração do sistema partidário não faz referência a seu caráter mais ou menos elitista. cessos de interação das RIGs segue caminhos diferentes, com consequências observáveis em seus sistemas partidários.

Observamos que, no Brasil, há uma estrutura fiscal descentralizada - ancorada em regras burocratizadas - e um processo decisório centralizado, que conformam questões fundamentais no que tange à história das relações intergovernamentais no país. Notamos que, de forma similar ao Brasil, a Argentina possui um processo legislativo centralizado. Porém, diferentemente do Brasil, possui uma estrutura fiscal centralizada, na qual os conflitos federativos parecem ser resolvidos fora da arena parlamentar e dirimidos em negociações bilaterais entre o Poder Executivo Nacional (PEN) e os governadores. No entanto, os resultados dessas negociações têm alcançado, ao longo do tempo, equilíbrios instáveis. Como consequência, podemos apontar a própria rigidez institucional do sistema de distribuição federal de recursos.

Por último, em relação ao sistema partidário, os países em questão mostram tendências diferenciadas: enquanto o brasileiro está se consolidando com bases partidário-eleitorais definidas e se estruturando em votações para o Legislativo com nexo partidário (Figueiredo, 2005), o argentino caminha em direção à maior territorialização, processo mediante o qual o comportamento das forças políticas de seus líderes e de seus eleitores se torna cada vez mais local (Calvo; Escolar, 2005).

Desse modo, as diferenças entre os resultados das dinâmicas políticas observadas nos dois países mostram que as características da divisão institucional de poder - inerente ao federalismo - são insuficientes para definir o potencial de gerenciamento da agenda de políticas públicas. Portanto, neste trabalho, buscaremos analisar o sistema de partidos no Brasil e na Argentina como elemento central para a compreensão da capacidade de racionalização das relações intergovernamentais e, consequentemente, para a implementação de políticas públicas nacionais e intertemporais. 
O texto apresenta quatro partes. A primeira divide-se em quatro seções: as três primeiras discutem com importantes correntes da literatura contemporânea o impacto do federalismo no funcionamento do Estado; na quarta seção, apresenta-se o argumento proposto e a hipótese dele decorrente. A segunda e a terceira partes se ocupam da análise dos casos empíricos. Na última, a modo de conclusão, apresentam-se algumas considerações comparativas.

\section{FEDERALISMO, SISTEMAS PAR- TIDÁRIOS E O FUNCIONAMENTO DO ESTADO: abordagens teóricas}

$\mathrm{O}$ argumento central do artigo pressupõe que o conflito é inerente aos contextos federais. Nesse sentido, a implementação de políticas que busquem modificar o status quo ${ }^{4}$ estará condicionada à capacidade das federações de gerarem mecanismos eficientes de coordenação entre suas partes constitutivas.

Assim, defendemos que é a forma como se estrutura a relação política entre o governo central e as subunidades o que irá determinar a capacidade das federações de resolverem problemas de coordenação entre os atores dos diferentes níveis de governo. Por isso, para entender o funcionamento das federações e suas implicações nas políticas públicas é preciso analisar a maneira como são canalizadas as clivagens intergovernamentais nos sistemas partidários de cada país.

Esta primeira parte consiste em uma discussão com as principais linhas teóricas que analisam o impacto do federalismo no funcionamento do Estado e tem por objetivo a construção do marco analítico proposto.

\footnotetext{
${ }^{4}$ Isto não quer dizer, contudo, que o status quo não seja opção possível e racional. No entanto, a fim de mantê-lo em contexto dinâmico (como é o da política) é necessário que exista um processo reativo permanentemente acionado e atento aos estímulos tanto internos quanto externos, pelo que a manutenção do status quo demanda, também, readaptações nas relações de poder, para que estas sobrevivam.
}

\section{Origem e reprodução dos federalismos mo-} dernos

William Riker $(1964,1975,1974)$ examina os federalismos do século XX, centrando seu interesse nos mecanismos que promovem sua consolidação e sua reprodução ao longo do tempo. Para o autor, a centralização dos federalismos modernos é consequência do desenvolvimento da sociedade através de um processo político de barganha constitucional entre atores racionais com motivações específicas. Induz maior eficiência na coleta e na distribuição de impostos, do mesmo modo que em matéria de defesa nacional. ${ }^{5}$

Segundo Riker (1964, 1975), o federalismo moderno se define com base no grau de autonomia de cada parte constitutiva e, principalmente, na sua capacidade de gerar equilíbrio de interesses entre as diversas instâncias de poder. A conexão, no entanto, entre os interesses das partes e o interesse coletivo irá se refletir em seu sistema partidário. Desse modo, se a centralização é que irá legitimar, em princípio, o federalismo, serão as características de seu sistema partidário que estimularão sua preservação. Para tal, torna-se indispensável que as unidades constitutivas recebam, ao longo do tempo, os incentivos necessários para reproduzir as fontes de legitimidade da federação, ao mesmo tempo em que o governo central também se sinta compelido a respeitar o pacto inicial.

Riker (1964) defende a importância de se ir além das estruturas formais do federalismo e a de investigar o impacto das relações de poder historicamente construídas e institucionalizadas em seu sistema partidário, para que se entendam os fatores que incidem na consolidação dos federalismos modernos. O sistema partidário, como elemento canalizador das preferências dos atores, influenciará a relação

\footnotetext{
${ }^{5}$ No entanto, diferentemente da perspectiva racional do neoinstitucionalismo, Riker toma as preferências dos atores como fixas.
} 
entre as subunidades e o poder central. ${ }^{6}$ Nesse ponto, a teoria proposta por Riker se diferencia das de autores da tradição institucionalista clássica: instituições formais não só não respondem por variações nos incentivos aos atores nos sistemas federais, como são passíveis de transformação a partir de sua interação com as organizações políticas. O sistema político ganha movimento.

Se o federalismo surge como pacto político entre atores racionais, e não sobrevive sem equilíbrio de forças, os graus de descentralização do sistema partidário e seu enraizamento na arena nacional, a partir do local, determinarão sua capacidade de retroalimentação. Nesse contexto, os resultados da distribuição formal de competências entre as subunidades e o governo central estarão relacionados aos graus de centralização ou descentralização de seu sistema partidário.

Uma segunda linha de pesquisa aponta, contudo, para a importância das instituições formais dos sistemas federais como variáveis-chave para o entendimento de seus resultados políticos e econômicos. De acordo com Stepan (1999), as especificidades do sistema partidário e as configurações da divisão constitucional de poder nas democracias - os graus de sobre ou sub-representação legislativa das uniA dades federativas, a abrangência das prerrogaN. tivas das subunidades em relação às políticas $\stackrel{8}{i} \mathrm{n}$ nacionais e o grau de poder de elaborar políticas que a Constituição confere às subunidades - representariam fortes variáveis explicativas do desempenho federal, como também, e mais importante, espelhariam as assimetrias ineren$\stackrel{i}{\infty}$ tes à sua formação.

No entendimento do autor, o tipo de federalismo assumido ${ }^{7}$ e as razões de sua adoção ${ }^{8}$

- essas intimamente relacionadas às caracte-

${ }^{6}$ É importante ressaltar que essa definição não despreza a necessidade de um elemento jurídico, mesmo que se evite

s uma acepção puramente legalista e formal. De fato, é na

I. Constituição, segundo Riker, que se devem encontrar os

dispositivos essenciais para reforçar a descentralização do sistema de partidos.

${ }^{7}$ Se demos constrainig ou demos enabling.

${ }^{8}$ Para "unir" ou "manter a união". rísticas de sua sociedade ${ }^{9}$ - dizem muito a respeito dos resultados das políticas públicas, já que se conectam diretamente à capacidade de gerar o consenso necessário para implementar políticas universais. Os limites do que é, por consenso, área de interesse do governo de uma unidade territorial ou preocupação do governo federal estão em permanente fluxo. Nesse sentido, o equilíbrio é induzido pela estrutura.

O trabalho de Stepan (1999) destaca a relação entre os traços institucionais dos sistemas federativos e as assimetrias subjacentes a esses países. As instituições federais interagem com essas assimetrias, concedendo às unidades constituintes da federação determinados direitos políticos, obrigações e representação nos organismos do governo nacional. Em alguns casos, essas instituições concordam com as assimetrias, ao passo que, em outros, as compensam. De acordo com essa perspectiva, o desenho das instituições federais teria implicações sobre o modo como o poder é distribuído entre atores fundamentais em um sistema federativo (Gordin, 2007). As instituições federais conformam (e reformam) a distribuição espacial de poder entre atores com base territorial e a distribuição institucional do poder entre atores localizados em diferentes "níveis" da sociedade federal (Gibson; Calvo; Falleti, 2003). São as instituições que modelam o comportamento dos atores através dos incentivos que produzem. Contudo, ao absorverem as assimetrias - tanto políticas como econômicas da sociedade da qual emergem, essas instituições acabam não só por refletir, mas também por reforçar as condutas cooperativas ou não cooperativas que as fundamentam.

Tanto Riker (1962, 1964, 1974, 1975) como Stepan (1999) concordam com a afirmação de que, em qualquer sistema político, a adoção de nova linha de ação governamental que se desvie do status quo requer a concordância de atores específicos. Por outro lado,

${ }^{9} \mathrm{O}$ autor se refere às características das sociedades que formam o Estado federal: mononacionais, multinacionais ou multiculturais. 
a capacidade de os governos implementarem políticas públicas vai depender das características das instituições envolvidas no processo decisório, pois a capacidade de iniciar reformas está diretamente ligada às características dos veto players institucionais e partidários presentes no processo decisório (Tsebelis, 1997). Todavia, para Stepan (1999), são as instituições federais e seu sistema partidário que cristalizam os incentivos os quais direcionam o acionar dos atores ao longo do tempo. Riker (1962, 1964, 1974, 1975) destaca o papel essencial do sistema de partidos como variável endógena, que pressupõe certo dinamismo institucional. O conflito intergovernamental, no entanto, é considerado a partir de uma perspectiva unidimensional, ou seja, ele se intensifica na medida em que o governo central tende a atuar de forma discricional.

Em relação à hipótese que permeia o presente trabalho, fazemos duas considerações. Com Riker, defendemos a relevância da análise sobre o conflito intergovernamental para compreender a configuração do sistema partidário e seu reflexo no funcionamento federal. Com Stepan, advertimos sobre a possibilidade de que, pela interação repetida entre atores intergovernamentais e partidários, modifiquem-se as instituições que promoviam ou evitavam uma dinâmica não cooperativa.

\section{O Federalismo e o mercado desde a nova economia institucional}

Este enfoque pressupõe que as instituições sejam influenciadas pelo contexto e que, longe de serem construções exógenas ao funcionamento da sociedade, constituam parte de um conjunto interativo de regras formais e informais que explicam as especificidades do comportamento político de dada sociedade. Os atores racionais, no entanto, longe de seguirem uma mentalidade unicamente utilitária ou instrumental, definem seu comportamento com base em uma estrutura de incentivos, que é o reflexo do conjunto de in- centivos, de restrições e de vivências passadas, as quais conformam suas escolhas em determinada arena institucional.

Dessa perspectiva analítica, a preocupação central para o estudo sobre as consequências do federalismo no desempenho econômico reside na capacidade de o sistema gerar um comprometimento suficientemente crível entre os membros da federação para aceitarem e cumprirem acordos pactuados. Tal comprometimento deve estar atrelado à capacidade de as instituições promoverem um contexto de credibilidade, de modo a possibilitar interações estáveis e acordos de longo prazo.

De acordo com o marco teórico adotado, a política pública é o resultado de um tecido ou rede de contratos entre atores políticos. Para entender o tipo de políticas públicas implementado em determinada sociedade, é preciso analisar os incentivos dos diversos atores no contexto desse tecido contratual, em sua totalidade. Faz-se necessário, portanto, observar as políticas públicas e o comportamento dos atores como resultado de um equilíbrio geral institucional. Assim como as políticas públicas resultam desse tecido ou rede de contratos, as instituições políticas consistem na estrutura de governança daquela política pública. Contudo, é importante ressaltar que os incentivos previstos pelo contrato (instituiçóes) podem não ser relevantes caso sua estrutura de governança (rede de instituições) seja ineficiente em assegurar o cumprimento do acordado.

Em trabalho seminal, Weingast (1995) preocupado em entender como um sistema federal é capaz de produzir instituições que preservem um mercado comum e promovam, ao mesmo tempo, o desenvolvimento econômico - propõe a construção de uma teoria positiva do constitucionalismo. O autor defende que certas instituições podem induzir os atores subnacionais a cooperar com o governo central, alterando suas preferências futuras através da implementação do Federalismo Protetor de Mercado (Market Preserving Federalism - 
MPF, a partir de agora). ${ }^{10}$

Em consonância com trabalho anterior em parceria com North, o argumento ressalta a centralidade da imposição de limites às prerrogativas do governo central no que se refere à política fiscal. Essa limitação, ao diminuir as possibilidades de discricionariedade, incentivaria maior cooperação entre os poderes. (North e Weingast, 1989) O MPF seria legitimado pelos cidadãos mediante a percepção, ex post, dos benefícios oriundos da proteção do mercado comum como bem comum (common pool) e da internalização das consequências negativas da não cooperação.

Contudo a contribuição principal de Weingast (1995) é sua preocupação em explicar os fatores que incentivam a reprodução de um sistema federal impulsionador tanto da economia de mercado como do desenvolvimento econômico. Para tanto, ele introduz a ideia de dinamismo nas preferências ${ }^{11}$ dos atores dentro de dada arena institucional (ou estrutura de incentivos). O autor, para tal, adota como marco conceitual a noção de estrutura de governança, propondo alguns princípios constitucionais necessários a uma sociedade federal para que ela possa se desenvolver em consonância com as bases políticas essenciais ao surgimento de uma economia de mercado A capaz de perdurar ao longo do tempo.

Na concepção de Weingast (1995), se o federalismo a la Riker promove um sistema sustentável de descentralização política, é a descentralização econômica do MPF que incentiva sua reprodução através da limitação de atividades predadoras ou de rent-seeking no setor público e do desestímulo à formação de coalizões distributivas. Esses benefícios são consequência do estímulo à competição entre as subunidades com base na descentralização econômica e na mobilidade das fontes de capital e de trabalho, o que se refletirá, finalmente,

${ }^{10} \mathrm{O}$ conceito de mercado comum aplicado às premissas deste trabalho pressupõe a ideia de bem coletivo.

${ }^{11}$ Ao contrário da visão instrumentalista e utilitária da teoria clássica da Escolha Racional. na qualidade das políticas públicas. O maior desenvolvimento econômico através do MPF, induzido pelo aumento paulatino na qualidade das políticas públicas, será o motor de reprodução do sistema. Os atores envolvidos seriam impelidos a protegê-lo como resposta aos benefícios que produz, cujas bases institucionais são inscritas na Constituição.

Na teoria proposta por Weingast (1995), a Carta Magna é a ferramenta de coordenação par excellance das relações intergovernamentais, e o respeito a ela irá legitimar o próprio sistema. É o que impele o governo central a não ultrapassar seus limites de ação, do mesmo modo que induz as subunidades a protegerem o mercado comum, produzindo um comprometimento crível entre os membros do pacto federal (North; Weingast, 1989). O desenvolvimento econômico tem de estar atrelado ao desenvolvimento político da sociedade, no sentido da internalização dos benefícios da preservação do sistema.

A reflexão teórica de Weingast (1995) remete a algumas considerações. Em primeiro lugar, as prerrogativas acima mencionadas deixam aberta uma importante lacuna ao tornar sua análise dicotômica: certos federalismos preservam o mercado, outros, não. Assim, o autor elimina a possibilidade de se considerar a existência de variações dentro do federalismo e o dinamismo que ele suscita. Em segundo lugar, Weingast não explica o processo histórico pelo qual foi possível alcançar o consenso necessário à implementação de determinado tipo de instituição, ou seja, para a aprovação de uma reforma constitucional que execute o MPF. Por conseguinte, o autor não toma em conta possíveis fatores históricos e contextuais que, ao imprimirem certos graus de conflito intergovernamental, dificultam a consecução de resultados cooperativos. Isso se deve ao fato de que, como o autor defende, o êxito de um federalismo de mercado depende não somente das peripécias da engenharia institucional per se, mas do quanto a reforma é capaz de modificar a estrutura de incentivos dos cidadãos. 
O trabalho de Stasavage (2002) reforça as críticas. Esse autor alega que, apesar de ser possível atingir um comprometimento crível através da limitação das prerrogativas do governo central, é preciso considerar que a barganha entre atores políticos, em suas múltiplas dimensões, pode levar a resultados diferentes quando aplicada a outros contextos. De acordo com Stasavage (2002), o comprometimento pode estar mais relacionado à emergência de um novo ciclo político, resultante de mudanças na distribuição de poder dentro do Parlamento, do que ao impacto da limitação do governo através da descentralização de responsabilidades.

Com base na discussão desses trabalhos, argumentamos que o comprometimento dos atores na preservação de um mercado comum - no caso, um Estado Federal - está associado às características das coalizões políticas que se formam em determinados momentos históricos. No entanto, falta elucidar de que maneira essas modificações na estrutura de incentivos dos atores podem se reproduzir ao longo do tempo. Se adotarmos como variável explicativa as características das coalizões que se formam em dado momento histórico e seu impacto na institucionalização do sistema, restaria explicar os mecanismos institucionais que precisam ser ativados para que, findo determinado ciclo político-econômico, a preservação do mercado comum ainda seja um valor coletivo.

Para responder a essa questão, a introdução da noção de dependência de trajetória pode ser esclarecedora. O conceito, oriundo do neoinstitucionalismo histórico (North, 1990), proclama que a história importa no sentido de que as escolhas feitas pelas sociedades, no passado, tendem a se cristalizar como restrições, condicionando as escolhas dessas mesmas sociedades no presente e no futuro. Nesse sentido, defendemos que, em primeiro lugar, a existência de diversos equilíbrios é inerente ao processo histórico; em segundo lugar, que as características fundamentais dos diversos equilíbrios institucionais alcançados em cada país, ao longo do tempo, exercem impacto rele- vante nas características das políticas públicas e de seus resultados futuros. Por último, argumentamos que é preciso observar a relação entre as unidades que conformam o sistema federal e seu impacto no sistema partidário ao longo do tempo. Essa questão é discutida na próxima seção.

\section{Federalismo e relações intergovernamen- tais: a dimensão do conflito}

De acordo com Wibbels (2005), o paradigma proposto por Weingast (1995) subdimensiona fatores-chave na determinação do grau em que o conflito intergovernamental impede, em lugar de contribuir, para o desenvolvimento dos mercados. O autor ressalta que, para entender o desempenho econômico de um país federal, é preciso redirecionar o foco de análise e considerar o impacto dos processos políticos subnacionais no processo decisório central. A forma como são representados os interesses regionais no âmbito nacional e as características das coalizões que podem vir a se formar ao longo do tempo conformam as expectativas dos políticos e sua decisão de cooperar ou não.

Wibbels (2005) conclui que as políticas que visam a reformas econômicas (inclusive, para a implementação do MPF) constituem uma função de um constante processo de barganha entre os líderes nacionais e regionais pela sua sobrevivência política. O autor sugere que os processos de barganha política, modelados pelas características das instituições nacionais e subnacionais - ou seja, a dinâmica das relações intergovernamentais -, dizem bem mais sobre a capacidade de um governo de implementar reformas de longo prazo do que as análises puramente dicotômicas, centradas na discussão sobre os efeitos da centralização ou descentralização na resolução de problemas de ação coletiva. No entanto, apesar de ter como objetivo o desenvolvimento de uma teoria comparativa do conflito intergovernamental e de analisar como 
determinadas características das instituições subnacionais afetam os incentivos dos atores em relação à cooperação com a agenda federal, ele não indaga a respeito de fontes estruturais que (re)produzem ou intensificam o conflito intergovernamental como um todo.

Se aceitarmos que o federalismo se legitima pela sua capacidade de produzir benefícios coletivos para a nação e que esses benefícios estão relacionados à diminuição dos custos de transação, concluiremos que a legitimidade do sistema federal estará intimamente ligada à credibilidade do governo central quanto a cumprir seu papel ao longo do tempo como coordenador dos interesses da nação como um todo (North; Weingast, 1989; Riker, 1964; Weingast, 1995). Isso não quer dizer que não possa existir conflito entre as subunidades e o governo federal, ou que não haja diversidade entre seus membros. Contudo, para que o federalismo perdure, o conflito existente deve estar limitado pelo comprometimento de todos os membros com o sistema.

Nesse sentido, argumentamos que Wibbels não analisa a capacidade do poder central como agente privilegiado na coordenação dos interesses da federação, na construção de mecanismos que promovam o comprometimento com o todo, ou seja, com a federação.

- Tampouco adverte sobre as consequências do processo de interação entre atores diversos, dadas pela possibilidade de mudança institucional a partir de mudanças na estrutura de incentivos dos atores que participam do jogo (as subunidades e o governo central) através de um processo de aprendizagem, fruto do próprio dinamismo presente em sua interação vertical e horizontal ao longo do tempo.

$\mathrm{O}$ argumento central deste trabalho defende, então, que certas configurações político-institucionais presentes em períodos anteriores podem determinar estruturas de interação futuras que impelem comportamentos - mais ou menos - cooperativos entre os diversos níveis de governo. A explicação para essa questão reside na capacidade de aprendizagem dos atores intergovernamentais ao longo do tempo e seu impacto nos graus de credibilidade em relação ao cumprimento futuro dos pactos formulados. No que tange à capacidade de aprendizagem, ela é resultante do conhecimento gerado através de processos repetidos de interação entre instituições e atores dos diferentes níveis de governo. Neste ponto, vale novamente reforçar um dos argumentos centrais deste artigo: a relevância da noção de flexibilidade institucional ancorada em relações intergovernamentais comprometidas com a preservação do centralismo necessário à preservação do sistema federal como um todo.

Tendo como pano de fundo a discussão feita até aqui, a próxima seção apresentará o argumento conceitual proposto.

\section{Revisitando Riker: o argumento proposto}

Entendendo que a adoção do federalismo reflete um processo político de barganha constitucional entre atores racionais com motivações específicas, argumentamos que o federalismo é um bem coletivo cuja legitimidade reside na conexão entre as preferências dos atores locais e as políticas do governo central através de seus sistemas de representação. Sua sobrevivência depende, portanto, de sua capacidade de adaptação institucional face às mudanças na estrutura de incentivos dos atores das distintas esferas de poder (Riker, 1964; Weingast, 1995). Essas mudanças referem-se não só a possíveis modificações conjunturais, mas, como já foi dito, ao resultado da aprendizagem, que suscita processos repetidos de interação entre instituições e atores diversos. ${ }^{12}$

Seguindo esta lógica, argumenta-se que as características do funcionamento de um Estado federal estarão relacionadas com as modificações em seu sistema partidário, já que esse

12 Vale mencionar que grande parte da literatura recente tem destacado o conceito de aprendizagem institucional como fator-chave para compreender o estado atual da federação brasileira. Exemplo são: Nunes (1997), Mora (2002), Regis (2009) e Melo (2005). 
é o lócus central de expressão das preferências dos atores relevantes, para onde os processos de interação são canalizados. No entanto, é importante ressaltar que processos repetidos de interação não previnem resultados ineficientes ou não cooperativos. Ao contrário, como bem chama nossa atenção Stepan (1999), podem reproduzir mecanismos perversos de interação com resultados de soma zero.

Por isso, pensamos que, primeiramente, a forma como a construção da pólis federal $a b$ sorveu e modelou os conflitos preexistentes no sistema partidário e como, em momento posterior, esse sistema partidário provocará impacto na dinâmica federal constituem elementos centrais na análise das implicações do federalismo na resolução de problemas de ação coletiva. E, consequentemente, na implementação de políticas públicas gerenciadas pelo governo federal.

Desse modo, a capacidade de tornar o sistema federativo mais cooperativo será maior quando o sistema partidário, horizontalmente, for capaz de solucionar os problemas de ação coletiva. Porém essa horizontalidade - é importante aclarar - não se refere à completa nacionalização do sistema de partidos. Ao contrário, diz respeito a interesses locais projetados na arena nacional, sem que sua identidade seja dissolvida. Formam-se dois interesses integradores e não contraditórios: o nacional e o local. A fortaleza do sistema partidário reside na existência de um elo integrador que permita a flexibilidade necessária para absorver o dinamismo das relações intergovernamentais sem romper o jogo federal. O gráfico 1 resume o argumento.

Tendo como base esse marco teórico e as

Gráfico 1 - Argumento teórico proposto

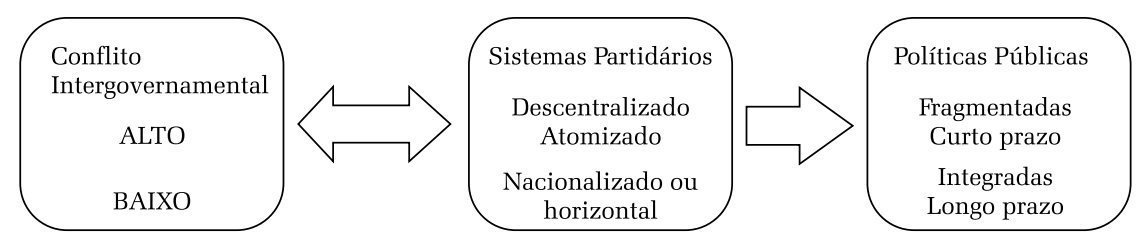

Fonte: elaborado pela autora. premissas principais dele decorrentes, a seção seguinte apresentará os dois casos que servirão para seu contraste. O que buscaremos apontar é como certos padrões de interação intergovernamental são modelados pelos sistemas partidários de cada país, com impacto direto nas características de suas políticas públicas.

\section{O CASO BRASILEIRO}

O ponto de partida de diversos estudos sobre o processo legislativo no Brasil baseia-se na dicotomia entre um país estadualista e refém dos "Barões da Federação" (Abrucio, 1998) e um país que demonstra, cada vez mais, uma lógica de interação intergovernamental mais coordenada.

Claramente, o ponto de referência que desafia a posição estadualista são os trabalhos de Figueiredo \& Limongi (1999, 2000, 2005) e de Cheibub, Figueiredo \& Limongi (2009), os quais, mesmo aceitando o peso significativo dos governadores na dinâmica política brasileira, destacam que a lógica estadual - segundo a qual a lealdade às bases eleitorais locais dominaria as preocupações nacionais e partidárias - é contra-arrestada por mecanismos institucionais e políticos que o governo federal lança mão a fim de construir coalizões de apoio às suas políticas.

A partir da Constituição de 1988 (CF88), a organização interna dos trabalhos legislativos caracteriza-se por ter um formato decisório centralizado, que se harmoniza com o papel preponderante do Executivo e por um Colégio de Líderes que esvazia o papel das comissões permanentes. As mudanças fundamentais instauradas em 1988 foram: a criação do Colégio de Líderes, com a prerrogativa de organizar o calendário das votações, o controle de emendas 
em plenário, ${ }^{13}$ o sistema de encaminhamento do voto ${ }^{14}$ e a centralização da escolha dos membros das Comissões Parlamentares, através da decisão dos líderes partidários, baseando-se a preferência na lealdade partidária e na expertise (Figueiredo; Limongi, 1999).

Por sua vez, no que tange ao poder de agenda do Executivo, os constituintes de 1988 preservaram as vantagens institucionais de que o regime militar havia dotado o Poder. ${ }^{15}$ Nas áreas de maior interesse, como tributação, orçamento, regulamentação e alterações na estrutura de cargos, salários e gratificações do funcionalismo público e da burocracia nomeada, o Executivo tem a prerrogativa exclusiva de propor legislação. Ao todo, são cinquenta e seis itens nos quais a União tem prerrogativa legislativa. A Constituição Federal de 1988 e, em grande medida, também as Cartas anteriores (ver nota de rodapé $\mathrm{n}^{\circ} 15$ ), deram amplos poderes legislativos ao Governo federal em políticas estratégicas, mesmo que elas fossem implementadas pelos governos subnacionais. ${ }^{16}$

No que tange aos interesses federais propriamente ditos, no Brasil, a formação de uma coalizão majoritária no Congresso Nacional é suficiente para que o Executivo federal consiga a aprovação de sua agenda, incluindo emendas que modifiquem a Constituição, sem que ユ. se exija aprovação ou revisão das instâncias จิ inferiores de governo quando se trata de inte-

${ }^{13}$ Quando um projeto é submetido à votação no plenário em regime de urgência, as emendas somente são consideradas quando contam com, pelo menos, um décimo da

Câmara ou dos Líderes cujas bancadas representam esse número.

$\dot{2}$

' ${ }^{14} \mathrm{O}$ encaminhamento do voto pelos líderes partidários diz - respeito à orientação de voto que os membros de seu par¿ tido devem seguir.

คे 15 É interessante notar que, no Brasil, em todas as Cons$>$ tituições, inclusive na monárquica de 1824, o Executivo ô foi contemplado com o direito de iniciativa legislativa. É T possível que, nesse domínio, o Legislativo tenha exercido supremacia no contexto das Constituições de 1824 (salvo $\varpi$ a fase parlamentarista) e de 1891. Mas, em 1934, a preت eminência presidencial já se manifestava, inclusive pela criação de uma esfera de iniciativa exclusiva ou reservada, a qual, com algumas modificações, se mantém na Constituição atualmente em vigor.

${ }^{16}$ Para uma análise detalhada, ver Simpson (2013) e Arretche (2009). resses subnacionais. ${ }^{17} \mathrm{O}$ jogo político começa e termina no Congresso Nacional.

Como destacam Santos (2002) e Amorim Neto \& Santos (2003), a mudança alocativa do Congresso, em comparação com o período de 1946-64, foi decisiva para uma "racionalização" do comportamento legislativo. A alteração no comportamento dos parlamentares refletiria, de acordo com os autores, uma solução ao problema de ação coletiva, já que os partidos passam a ter maior capacidade de negociação do que o legislador individual. Nesse sentido, o partido vai adquirindo maior peso no sistema político brasileiro, no qual o processo de formação de coalizões tem se mostrado mais estável (Cheibub, Figueiredo; Limongi, 2009; Santos, 2002).

Para testar a validade das afirmações, comparamos as taxas de disciplina e indisciplina partidária medidas pelo percentual da bancada que acompanhou o voto do líder de seu partido e as taxas de disciplina e indisciplina das bancadas estaduais. $\mathrm{O}$ que se quer observar é o peso dos incentivos estaduais vis-à-vis os incentivos partidários nas decisões de voto dos legisladores individuais em relação a uma agenda de políticas públicas propostas pelo governo federal.

Gráfico 2 - Taxas de disciplina de partidos e das bancadas estaduais (Dados agregados, 1989 - 2009)

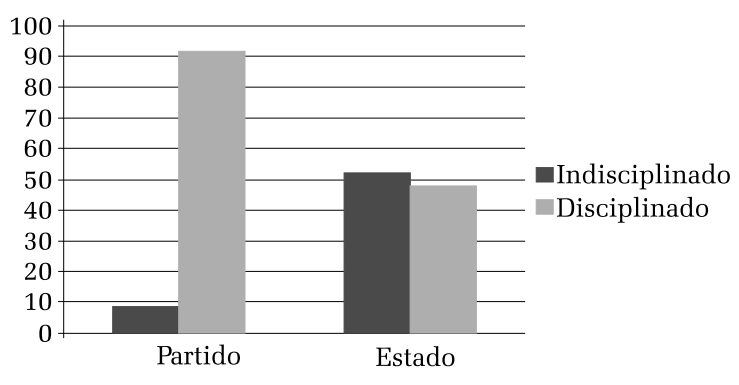

Fonte: Simpson (2015).

Nota-se que a disciplina partidária é o indicador mais elevado para o período entre 1989 e 2009 (mais de 90\%), ao passo que a taxa de disciplina das bancadas estaduais não che-

17 Diferentemente da Constituição argentina, como veremos mais adiante. 
ga a 50\%. Por sua vez, a análise das taxas de indisciplina mostra que há menor coesão nas bancadas estaduais em comparação à fidelidade_mostrada pelos deputados em relação a seu partido.

No Gráfico 3, a seguir, cotejamos os índices de Rice das bancadas partidárias e estaduais e seus desvios padrão. O índice de Rice refere-se à diferença absoluta entre o número de deputados que votaram de acordo com a indicação do líder de seu partido (ou do governo de seu estado) e dos que votaram contra essa indicação. Os resultados seguem a mesma tendência que as taxas de disciplina analisadas no Gráfico 2.

Gráfico 3 - Coesão das bancadas partidárias e das bancadas estaduais na Câmara de Deputados $(1989$ - 2009)

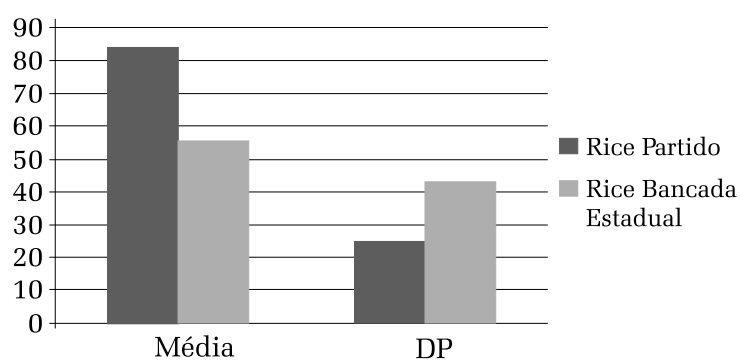

Fonte: Simpson (2015)

O índice de Rice das bancadas partidárias, analisado de forma agregada para o período estudado, é significativamente superior ao das bancadas estaduais. Como esperado, o desvio padrão ${ }^{18}$ relacionado ao índice de Rice das bancadas estaduais mostra maior e significativa volatilidade das intenções de voto dos legisladores de um mesmo estado.

Arretche (2004, 2007, 2009), por sua vez, argumenta que a centralização do processo decisório na arena federal afeta as oportunidades institucionais de veto dos governos territoriais no Brasil. Como foi mencionado

${ }^{18}$ O Desvio Padrão consiste em uma medida de dispersão em torno da média de uma variável determinada. Um baixo desvio padrão, por exemplo, indica que os pontos dos dados tendem a estar próximos da média ou do valor esperado. No que tange à nossa medição, os resultados dizem respeito a uma alta dispersão em relação aos interesses dos legisladores estaduais. anteriormente, em virtude de a União concentrar a autoridade de legislar sobre a maioria das responsabilidades em políticas dos estados e municípios, a arena federal acaba se transformando no lócus central das decisões sobre questões federais, acarretando que a maioria dessas questões seja processada na forma de legislação ordinária.

Apesar de os entes federativos terem formalmente a faculdade de administrar seus impostos, de implementar uma série de políticas públicas e de gastar recursos descentralizados, sua autonomia para tomar decisões a respeito dessas funções é limitada pela extensiva e detalhada Constituição Brasileira. De acordo com a CF 88, todas as iniciativas dos governos territoriais pressupõem regulação ${ }^{19}$ prévia por parte da União.

Um ponto relevante é que, na CF brasileira, diferentemente de outras federações, não há regras decisórias específicas sobre assuntos de interesse dos governos subnacionais. Os pontos de veto são basicamente as comissões legislativas e o plenário das duas casas. Contudo, o resultado dos processos, nesses dois âmbitos, como bem demonstra Santos (2002), é fortemente influenciado pelos recursos institucionais que o Executivo Federal e os líderes partidários lançam mão para a aprovação de medidas de seu interesse. ${ }^{20}$ Sendo assim, a ausência de regras institucionais que regulem particularmente os assuntos subnacionais e as prerrogativas de autoridade legislativa sobre assuntos federais enfraquece a capacidade de veto dos governos estaduais e municipais. Contudo isso não quer dizer que as subunidades sejam reféns das preferências do governo central.

Apesar do componente centralizador do

${ }^{19} \mathrm{~A}$ ressalva sobre regulação é importante quando comparada ao caso argentino. Se entendermos que aprovação e regulação são instâncias distintas, no caso argentino há exemplos que mostram como o processo que atravessa uma lei entre um momento e outro é utilizado como poder de negociacão pelo PEN, já que este último não só tem poder de modificar a lei antes de sua regulamentação, como tem, inclusive, a prerrogativa de regulamentar toda matéria aprovada. Fato que o dota de considerável poder de agenda (Rodríguez; Bonvecchi, 2004).

${ }^{20}$ Exemplos são o encaminhamento do voto e os pedidos de urgência anteriormente citados. 
processo decisório que o texto tem demonstrado, é importante destacar a presença de interesses particularmente locais e sua relevância no funcionamento da federação. Um indicador disso é, paradoxalmente, a própria existência de bancadas estaduais definidas no Congresso Nacional e a não linearidade de suas preferências. Arretche (2009) demonstra que, quando as iniciativas do Governo central incidem diretamente sobre as transferências constitucionais, sua aprovação é menos contundente. Esse aspecto demonstra a importância do caráter integrador do sistema partidário, mencionado na parte teórica e observado no caso brasileiro. A questão da existência dessas bancadas torna-se ainda mais destacável ao se analisar o caso argentino. Como se verá mais adiante, no Parlamento argentino, não há evidências de articulação formal de bancadas (bloques) provinciais no processo de votação de iniciativas do Executivo federal.

Por um lado, é importante repetir que o processo de recentralização posterior à CF 88 não representou um ponto de inflexão, mas sim um processo de aprofundamento da tendência contida na própria CF 88 , que contou fortemente com a participação dos atores subnacionais (Arretche, 2007, 2009). Esse ponto demonstra, como defende o argumento propos$\stackrel{A}{t}$, um processo de aprendizagem intergoverㄱ. namental que pode ser observado, inclusive, $\dot{8}$ nas políticas públicas. Dois exemplos relevantes são a aprovação da Emenda Constitucional 19 em 4 de junho de 1998 e a implementação da Lei de Responsabilidade Fiscal em 2000, N ambas ao redor de dez anos após a implemen¿. tação da CF88. A EC19/98 normatizou as di-

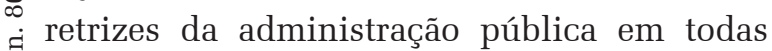
ले as esferas da federação e a LRF, entre outras $\overrightarrow{~ m e d i d a s, ~ p r o i b i u, ~ c o m o ~ e s t r a t e ́ g i a ~ d e ~ c o n t r o-~}$ le do endividamento, o refinanciamento pela União de dívidas subnacionais e, mediante a Lei Complementar 101 (LRF) desviou do Senado a prerrogativa sobre as decisões de gasto estadual, o que visava a eliminar o componente político do processo decisório em torno do endividamento. Ambas foram aprovadas mediante discussões no plenário e se dividiram em clivagens ideológicas e não federais.

Por outro lado, trabalhos análogos (Arretche, 2007, 2009; Arretche; Rodden, 2004; Cheibub; Figueiredo; Limongi, 2009, Simpson, 2013, 2015) têm demonstrado que as bancadas estaduais não se comportam, em geral, como um ator coletivo, o que se verifica pela variabilidade na coesão de suas decisões parlamentares (e nos índices de desvio padrão mostrados no Gráfico 3). Os trabalhos citados mostram que a indicação do líder partidário tem impacto maior na decisão do voto parlamentar do que a posição do governador de seu estado, o que independe do fato de o governador ser ou não do seu partido. A disciplina partidária é o que tem explicado o sucesso parlamentar dos presidentes na aprovação de medidas, em geral, e das medidas que atingem os interesses subnacionais, portanto, federalmente mais conflitivas, em particular.

De maneira concomitante observa-se que o sistema partidário brasileiro tende a uma maior previsibilidade, apesar da significativamente alta dispersão de poder (o Congresso, em 2015, organizava-se ao redor de mais ou menos treze partidos). No entanto, os índices de disciplina partidária mostram que os mecanismos de competição exerceram um efeito regulador sobre o sistema de partidos e das coalizões formadoras de governo.

No período de 1989-1994, os principais partidos (Partido dos Trabalhadores - PT, Partido Democrático Trabalhista - PDT, Partido da Frente Liberal - PFL, Partido Democrático Social - PDS, Partido do Movimento Democrático Brasileiro - PMDB, Partido da Social Democracia Brasileira - PSDB e Partido Trabalhista Brasileiro - PTB) mostraram o índice de RICE entre 85,4 e 98 (Figueiredo \& Limongi, 1995) e, entre 2011 e 2014, a média da disciplina partidária foi de 94,57 .

Em termos da conexão entre o processo decisório nacional e a política partidária subnacional, Borges (2007) demonstra que houve 
diminuição das máquinas políticas dominantes nos estados mais conservadores, o que é explicado pelo autor em termos da ampliação do escopo de competição eleitoral nos dois níveis de governo e pela lógica da alocação de recursos, mais centralizada no governo federal.

Nesse sentido, índices de competitividade eleitoral subnacional para o período compreendido entre 1945 e 2006 mostram o significativo aumento da competição eleitoral nas eleições para as assembleias legislativas em todas as regiões brasileiras. No NE, por exemplo, o índice passou de 1,53 em 1986 a 3,15 em 2006. ${ }^{21}$ No Norte, o aumento, nas mesmas eleições, foi de 1,60 para 5,41. Em estados específicos, verificamos que, na Bahia, o índice foi de 1,83 para 3,37 em 2006; no Rio Grande do Norte, de 0,77 para 2,23; e em Roraima, de 2,50 em 1994 para 6,71 em 2006 (Santos, 2002).

Em síntese, na democracia brasileira, os partidos políticos podem escolher entre priorizar as eleições presidenciais, as eleições aos governos estaduais ou as disputas legislativas proporcionais. Mas, como os jogos se encontram imbricados (Melo, 2010), a opção pelas duas últimas não implica uma saída do jogo principal. Como o PMDB tem demonstrado, um partido pode ser bem-sucedido em uma estratégia que objetive fazer parte do jogo presidencial sem, no entanto, participar, de forma sistemática, da eleição propriamente dita.

Nota-se que o modelo de Estado federativo que surge da CF88 autorizou, por um lado, as elites do governo central a apresentarem iniciativas legislativas em todas as áreas relevantes de políticas públicas, em particular naquelas cuja execução é de competência de estados e municípios. Além disso, outorgou maior poder de agenda ao governo central, mas, por outro lado, dotou de grande flexibilidade as regras institucionais que regulam as áreas mais conflitivas das RIGs.

Uma evidência desse modelo é o fato de

${ }^{21}$ Note-se que o ano inicial da comparação é o de uma eleição anterior a CF de 88, o que demonstra também seu impacto nacionalizante. que a CF88 não criou um ambiente institucional que congelasse a distribuição original de autoridade de 1988, ao não estabelecer normas que dificultassem sua modificação. Isso nos leva a crer que as reformas da década de 1990 mostram continuidade nas preferências das elites intergovernamentais, ligadas a um modelo de Estado que vem sendo desenhado ao longo da história da federação brasileira. A opção por maior centralização, então, responde à necessidade de adaptação da estrutura institucional vigente frente a uma conjuntura de crise, tendo em mente que a capacidade intergovernamental de gerar comprometimentos críveis (credible commitment) é ampliada a partir de processos de aprendizagem ao longo do tempo.

As modificações observadas no sistema partidário evidenciam um processo de aprendizagem no qual se consolida uma racionale federal. A centralização do processo decisório e o caráter horizontal que passa a caracterizar a negociação partidária nacionalmente mostram que a resolução de problemas federais de ação coletiva tem seu instrumento canalizador nos partidos.

Na seção a seguir, analisamos o caso argentino.

\section{O CASO ARGENTINO}

Para introduzir o caso argentino, é preciso fazer, primeiramente, uma breve análise do processo de formação desse estado. A formação da nação argentina esteve marcada por fortes clivagens territoriais, fundamentadas pela ausência de consenso no que diz respeito aos parâmetros de autonomia e soberania de cada unidade constitutiva. Um dos pontos centrais para se compreender a dinâmica de seu federalismo na atualidade é o permanente duelo entre o chamado interior e a poderosa província de Buenos Aires. Esse duelo, que remete ao conflito entre Unitários e Federais entre os anos de 1816 a 1829, tingiu as rela- 
ções interprovinciais de uma tensão estrutural tão profunda que se transferiu a outros níveis de interação político-social. Exemplos são as dicotomias peronistas versus não peronistas, oposição versus governo, interior versus centro, trabalhadores versus oligarquias.

Essa tensão se vê refletida institucionalmente no seu rígido e centralizado sistema de redistribuição fiscal (Coparticipación Federal de Impuestos) e nos significativos graus de descentralização política. A estrutura institucional resultante incentivou a reprodução de um "processo de interação política encarcerado" (Mahoney; Schensul, 2011) que reveste as relações intergovernamentais, em particular, e as relações políticas, em geral, de um tom de confronto. As consequências desse tipo de processo reproduzem-se ao longo do tempo, mesmo quando passam a estar ausentes as causas que lhes deram origem. Esse aspecto transferiu os parâmetros de negociação intergovernamental para fora do campo legislativo e com base no âmbito redistributivo. Como resultado, o sistema fiscal tornou-se cada vez mais rígido, dificultando significativamente a implementação de regras que estimulem uma maior coordenação federal.

Dito isso, temos que a estrutura da política argentina se caracteriza por uma orgaA nização que reproduz a organização federal: os maiores partidos (Partido Justicialista - PJ $\stackrel{8}{\&}$ e Unión Cívica Radical - UCR) contam com uma autoridade nacional, uma provincial e uma local (Mustapic, 2000). Essa configuração descentralizada faz com que os líderes nacionais não tenham condições de controlar plenamente o comportamento dos seus membros, $\therefore$ pois ela se baseia em um sistema de múltiplas i lealdades, no qual o líder nacional se apoia em

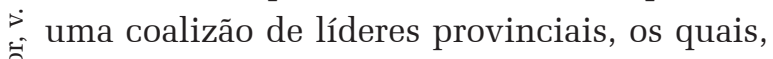
por sua vez, amparam-se em uma coalizão de líderes locais. Tal contexto é agravado pelo fato de que, mesmo sem existir formalização institucional, há acordo tácito entre os principais partidos políticos, pelo qual se estipula que os chefes dos executivos (nacional ou provin- ciais) também sejam os chefes do partido. Ou seja, o Presidente da República é, em geral, também o chefe nacional de seu partido e, no âmbito subnacional, o chefe provincial do Partido é, em geral, o governador. Nas províncias em que o partido não é governo, a estrutura de poder interna segue a mesma lógica: uma pessoa ou um pequeno grupo domina a dinâmica do partido em nível provincial.

Mustapic (2000) ressalta que a organização descentralizada dos partidos políticos e suas regras de competição interna (eleições diretas abertas), as do PJ e da UCR em particular, conspiram contra a capacidade de os líderes nacionais descansarem na disciplina dos legisladores. De acordo ainda com a autora, como é fraca a densidade ideológica nas divisões partidárias internas, ao mesmo tempo em que existe curta distância ideológica entre os partidos políticos em geral, a coesão entre os líderes e seus correligionários baseia-se nos resultados eleitorais, fato que explica os permanentes realinhamentos internos antes e depois das eleições. Por sua vez, na Constituição argentina de 1994, diferentemente da CF88 brasileira, as subunidades têm a última palavra nas decisões relativas a questões que envolvem seus interesses fiscais e têm total autonomia na gestão e na organização da administração pública provincial.

Nesse contexto, Eaton (2005) sugere que a dinâmica das relações intergovernamentais embebidas nessa estrutura política provoca uma considerável rigidez institucional, a qual deriva da incapacidade de superar problemas de ação coletiva, que se aprofundam, em grande parte, como consequência da descentralização da estrutura política, somada a um centralismo fiscal. A histórica centralização da arrecadação - ou seja, a separação entre o recolhimento de impostos e o gasto - tem conduzido a um elevado desequilíbrio fiscal vertical, que, como resultado da limitada autonomia fiscal, torna as subunidades, em sua maioria, altamente dependentes das transferências governamentais. No entanto, a estrutura das re- 
lações políticas nesse país, ao circunscrever núcleos de poder - em muitos aspectos autônomos - ao âmbito subnacional, assegura considerável poder aos governadores como líderes políticos. Essa conjuntura gera um contexto de conflito intergovernamental intermitente.

Os trabalhos de Calvo \& Escolar (2005) e de Simpson (2013) demonstram que, diferentemente do caso brasileiro, temos que o impacto do conflito intergovernamental nos processos de reforma dos anos 1990, na Argentina, aprofundou a territorialização do sistema partidário. Mais especificamente, em termos de seu reflexo nas políticas públicas, as características das políticas de descentralização da saúde e da educação, levadas a cabo durante o governo de Menem (1989-1999), fortaleceram o poder dos atores locais como resultado não esperado do aumento dos repasses federais para cobrir a transferência dos serviços sociais sem, contudo, haver a implementação de mecanismos de supervisão da gestão dos recursos transferidos. Esse contexto impulsionou uma ainda maior separação entre os sistemas políticos nacionais e provinciais.

As razões principais para tal fortalecimento residem na capacidade de distribuição discricionária de recursos políticos, econômicos e simbólicos a eleitorados que se encontram territorialmente concentrados. Os governadores e, em poucos casos, os prefeitos ${ }^{22}$ exercem considerável influência nas decisões de gasto em política pública tanto através de seu controle direto do orçamento provincial como pelo seu controle discricionário de programas financiados pelo governo federal. ${ }^{23}$

${ }^{22}$ Um ponto importantíssimo é o fato de os repasses dos recursos da coparticipacão para os níveis locais (municípios) serem de responsabilidade dos governos provinciais. Diferentemente do Brasil, os municípios argentinos não são considerados constitucionalmente entes federais. Essa questão permite que o governador utilize os próprios repasses federais como ferramenta de barganha política com os diversos intendentes (prefeitos), o que incentiva a construcão e o fortalecimento de nichos políticos provinciais a partir do controle das instituições partidárias e eleitorais. Para análise detalhada, ver Calvo \& Escolar, 2005, capítulo 5.

${ }^{23}$ No Brasil, o processo de descentralização das políticas sociais incentivou, ao contrário da Argentina, a ampliação da competitividade subnacional, o que resultou no enfraquecimento, de um modo geral, de estruturas "oligárqui-
Segue-se que o fortalecimento dos sistemas políticos subnacionais vis-à-vis o nacional tornou mais complexo não só o processo decisório, mas igualmente as próprias relações intergovernamentais. A tendência à atomização dos sistemas partidários provinciais explica a fragmentação maior do processo decisório no âmbito nacional (Calvo et al. 2001).

O Gráfico 4, a seguir, ilustra essa tendência, ao referir-se ao número efetivo de partidos que competem nas eleições presidenciais, para deputados nacionais e deputados provinciais nos anos de 1983 a 2003.

\section{Gráfico 4 - NEP para as Eleições Presidenciais, deputa- dos federais, provinciais e para governador} (1983-2003)

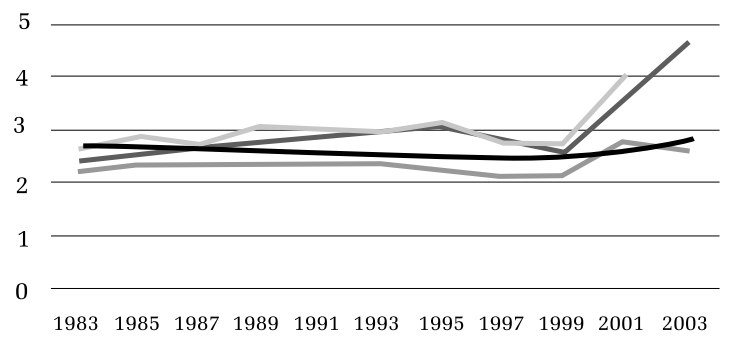

- Nep PRES — Nep Dnac —Nep Dprov — Nep Gov

Fonte: adaptado de Calvo \& Escolar (2005).

Pode-se observar que, enquanto os níveis de competição efetiva para as eleições de presidente e de deputados federais aumentam, o número de partidos efetivos que competem nas eleições para deputados provinciais e para governador mostra tendência contrária.

No âmbito nacional, Jones, Hwang e Micozzi (2009), analisando o comportamento dos legisladores durante 1989 e 2007, através do exame das votações nominais na Câmara de Deputados, demonstram que as clivagens nessa Casa direcionam-se a uma única dimensão: quem vota com o governo e quem vota com a oposição. Isso se deve também ao sucesso do

cas" de poder. Um dos vetores institucionais de diferenciação nos processos de descentralização é a existência, no Brasil, de condicionalidades no repasse das verbas e de lineamentos gerais sobre sua implementação administrados pelo Governo Nacional. 
partido majoritário na imposição da agenda legislativa mediante sua capacidade de funcionar como cartel: a liderança partidária do partido majoritário lança mão de seu poder de agenda para dominar o processo legislativo. Suas prerrogativas consistem em bloquear aquelas iniciativas que vão contra as preferências do partido e dar passagem àquelas que $o$ apoiam. A oposição, no entanto, ao não possuir poder de agenda, nem positivo nem negativo, é relegada a um papel reativo.

Como resposta a um problema de ação coletiva, é lógico esperar que a dinâmica do processo legislativo nacional passe a centrar-se na competição entre governo e oposição, em vista dos maiores custos e dos menores ganhos de uma oposição fragmentada. A clivagem federal propriamente dita fica de fora do âmbito legislativo e é exposta pelos processos de barganha bilateral entre representantes dos executivos.

Um exemplo que esboça o impacto do conflito intergovernamental no processo decisório é o Pacto Fiscal I de 1992. É preciso apontar que esse Pacto, assim como outros acordos similares, ilustra o atributo central das relações intergovernamentais verticais na Argentina, mencionado anteriormente, que é o predomínio das relações entre executivos em contraposição A ao processo decisório no âmbito legislativo.

Em meio a uma conjuntura de grave crise fiscal, o governo argentino propôs o Pacto Fiscal I, denominado "Acuerdo de Compromiso Federal entre el Gobierno Nacional y los Gobiernos Provinciales", que modificava a distribuição primária dos recursos coparticipáveis, com o objetivo de auxiliar as províncias com desequilíbrios fiscais no pagamento das obrigações previdenciárias nacionais, entre outros gastos operativos. Mais especificamente, o Pacto I reduzia em 15\% os recursos destinados às províncias e os transferia aos gastos de previdência social (os quais representavam sério déficit de caixa), de responsabilidade da União. A busca de maior centralização econô- mica $^{24}$ respondia aos efeitos das modificações na Coparticipação aprovada pelos legisladores em 1987, as quais determinavam que as províncias deveriam receber em torno de 57\% dos recursos coletados pela Nação e não mais por volta de 48\%, como previa a Lei $\mathrm{n}^{\circ} .20 .221$ (Simpson, 2013).

Com o fim de aprovar essa modificação, entretanto, os governadores exigiram um piso mínimo para as transferências provinciais (nenhuma província poderia receber benefícios menores do que $\$ 740$ milhões de pesos), o que não só engessou o orçamento como o tornou inviável anos mais tarde, com o contínuo aprofundamento da crise fiscal. O Pacto Fiscal I também previa que tanto o Governo Federal e o Governo da Cidade de Buenos Aires, como as Províncias se comprometiam a não incrementar seus níveis de gastos primários, na medida em que apresentassem ainda desequilíbrios fiscais, mesmo que potenciais, e comprometiam-se a sancionar uma "Ley de Solvencia Fiscal" e uma "Ley de Administración Financiera”"25 (Simpson, 2013).

Contudo, como mostra o Quadro 1 a seguir, nem todas as províncias seguiram o pactuado. Em relação à implementação das leis de solvência fiscal e à administração financeira, o comprometimento ficou longe de ser unânime.

É interessante fazer duas observações a respeito dos dados. Em primeiro lugar, chama a atenção, em termos federativos, a falta de coordenação horizontal entre as subunidades e a falta de cooperação vertical entre elas e o governo central, uma vez que apenas $30 \%$ das subunidades (apenas oito das vinte e quatro) aderiram completamente às regras preestabelecidas. Em segundo lugar, é lógico supor que

${ }^{24} \mathrm{~A}$ recentralização econômica concerne à centralização dos recursos nas mãos do Executivo Federal; não se refere à centralização e à federalização da política econômica.

${ }^{25}$ As normativas presentes nas Leis foram sancionadas com base nas diretivas da Lei de Administração Financeira e dos Sistemas de Controle do Setor Público Nacional (Ley $\mathrm{n}^{\circ} 24.156$ de Administración Financiera y de los Sistemas de Control del Sector Público Nacional). A Lei completa pode-se ver em: <http://www2.mecon.gov.ar/foro_presupuesto/otrasnorm/ley24156del30-9-92administracionfinanciera.pdf $>$ 
Quadro 1 - Leis de solvência fiscal e à administração financeira

\begin{tabular}{|c|c|c|c|}
\hline Províncias & \multicolumn{2}{|c|}{ Leis de solvência fiscal } & Adm. financeira \\
\hline GCBA & \multicolumn{2}{|c|}{ Não possui } & Lei $N^{0} 70$ \\
\hline BUENOS AIRES & \multicolumn{2}{|c|}{ Não possui } & Não possui \\
\hline CATAMARCA & $26 / 12 / 2000$ & $\begin{array}{c}\text { Lei } N^{\circ} 4997 / \mathrm{m} \text {. } \\
\text { Lei } N^{\circ} 5017\end{array}$ & Lei $N^{\circ} 4938$ \\
\hline CORDOBA & $25 / 03 / 2000$ & Lei $N^{\circ} 8836$ & Não possui \\
\hline CORRIENTES & \multicolumn{2}{|c|}{ Não possui } & Não possui \\
\hline CHACO & $17 / 05 / 2000$ & Lei $N^{\circ} 4725$ & Lei $N^{\circ} 4787$ \\
\hline CHUBUT & \multicolumn{2}{|l|}{ Não possui } & Lei $\mathrm{N}^{\circ} 4626$ \\
\hline ENTRE RIOS & \multicolumn{2}{|c|}{ Não possui. } & 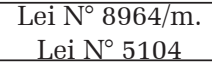 \\
\hline FORMOSA & $31 / 12 / 1999$ & Lei $N^{\circ} 1298$ & Lei $N^{\circ} 1180$ \\
\hline JUJUY & \multicolumn{2}{|c|}{ Não possui } & Lei $N^{\circ} 4958$ \\
\hline LA PAMPA & \multicolumn{2}{|c|}{ Não possui } & Não possui \\
\hline LA RIOJA & \multicolumn{2}{|c|}{ Não possui } & Lei $N^{\circ} 6425$ \\
\hline MENDOZA & $13 / 01 / 2000$ & Lei $N^{\circ} 6757$ & Não possui. \\
\hline MISIONES & $04 / 05 / 2000$ & Lei $N^{\circ} 3648$ & Não possui. \\
\hline NEUQUEN & \multicolumn{2}{|c|}{ Não possui } & Lei No 2141 \\
\hline RIO NEGRO & $17 / 01 / 2001$ & Lei $N^{\circ} 3502$ & Lei No 3186 \\
\hline SALTA & 27/05/1999 & Lei $N^{\circ} 7030$ & Não possui. \\
\hline SAN JUAN & 04/01/2001 & Lei $N^{\circ} 7119$ & Lei $N^{\circ} 6905$ \\
\hline SAN LUIS & 03/08/1999 & Lei $N^{\circ} 5164$ & Lei $N^{\circ} 5172$ \\
\hline SANTA CRUZ & \multicolumn{2}{|c|}{ Não possui } & Não possui \\
\hline SANTA FE & \multicolumn{2}{|c|}{ Não possui } & Não possui \\
\hline S. DEL ESTERO & \multicolumn{2}{|c|}{ Não possui } & Não possui \\
\hline TUCUMAN & 09/09/1999 & Lei No 6964 & Lei $\mathrm{N}^{\circ} 6970$ \\
\hline T. DEL FUEGO & $22 / 08 / 2000$ & Lei $N^{\circ} 487$ & Lei $N^{\circ} 495$ \\
\hline
\end{tabular}

Fonte: adaptado de Simpson (2013).

os dados observados antecipam as minguadas chances de se alcançarem os resultados políticos e econômicos esperados pelo Pacto.

Nesse sentido, Gordin (2007) destaca a existência de mecanismos institucionais que fortalecem o status quo ineficiente. Assim, acredita-se que as clivagens existentes nos sistemas partidários, as quais são um reflexo dos históricos conflitos intergovernamentais, terminaram, de um modo geral, materializadas nas características de suas políticas públicas, em suas políticas fiscais, mais especificamente, e no aprofundamento das tendências centrífugas ou centrípetas contidas em seus sistemas de representação. Como resultado, as negociações políticas estruturam-se nos termos do que Tsebelis (1997) chamou de Nested
Games, ou seja, processos políticos nos quais os atores são obrigados a tomar decisões tendo como base duas ou mais arenas políticas superpostas, mas não imbricadas (integradas).

Essa conjuntura seria o resultado daquilo que, como já vimos, as características de seu sistema partidário espelham nas clivagens inerentes ao seu sistema federal. Elas fazem com que os conflitos políticos sejam transferidos para a arena intergovernamental e personificados na figura do governador e na do Presidente da República (Calvo; Escolar, 2005).

Em termos das premissas levantadas por este trabalho, argumentamos que a estrutura dual que o sistema de partidos argentino adquire, longe de canalizar a interação intergovernamental para uma direção mais coope- 
rativa, tende a aprofundar o conflito federal como resposta à ambiguidade da distribuição de autoridade. A implementação da agenda do governo federal, portanto, está condicionada à capacidade de negociação do Executivo, como chefe partidário nacional, com os chefes partidários provinciais que, na maioria das vezes, são de seu mesmo partido. É a partir dessa lógica que se apreende o caráter dual da estrutura política argentina e a dificuldade, através de seu sistema partidário, de alcançar uma dinâmica intergovernamental com maiores graus de cooperação.

\section{CONCLUSÕES COMPARATIVAS}

Esse artigo entende o federalismo como um bem coletivo cuja legitimidade reside na conexão entre as preferências dos atores locais e as políticas do governo central através de seus sistemas de representação. Nesse sentido, sua sobrevivência depende de sua capacidade de adaptação (flexibilidade) face às mudanças na estrutura de incentivos dos atores das distintas esferas de poder. Essas mudanças referem-se não só a possíveis modificações conjunturais, mas ao resultado da aprendizagem que suscita processos repetidos de interação entre insti$\approx$ tuições e atores diversos ao longo do tempo. ণ No entanto, é importante ressaltar que, como demonstraram os casos em estudo, processos de aprendizagem não previnem resultados ineficientes ou não cooperativos.

No Brasil, observa-se uma dinâmica intergovernamental mais cooperativa, ancorada $\therefore$ em um processo legislativo com forte viés partidário e nacional. Esse contexto político mais i integrado, como foi dito anteriormente, facilita

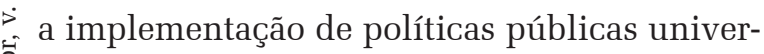
sais e de longo prazo. Observamos que a dimensão nacionalizante mostrou-se dominante na política brasileira, assim como a figura do estado na qualidade de gestor de políticas públicas. Sem querer supor ausência de conflito, o caso brasileiro mostra, ao longo do tempo, a continuidade de um modelo de Estado sob parâmetros definidos, mesmo que flexíveis. Tal modelo possibilita haver um processo de aprendizagem intergovernamental que incentiva dinâmicas intergovernamentais mais cooperativas.

Já no caso argentino, o histórico conflito intergovernamental ajuda a compreender a crescente desnacionalização de seu sistema partidário e a consequente atomização de seus sistemas partidários subnacionais. Esse quadro dificulta o alcance de acordos intergovernamentais que permitam alcançar acordos de longo prazo necessários para a implementação de políticas públicas federais e intertemporais. A conflituosa relação intergovernamental impulsionou maior territorialização do sistema partidário, o que, ao dificultar a construção de uma agenda nacional consensuada, torna o federalismo menos cooperativo.

Enquanto o jogo político, na Argentina, mostra a multiplicação de arenas de negociação, criando joint-decision traps (Scharpf, 1988), no Brasil, a formação de uma coalizão majoritária no Congresso Nacional é suficiente para que o Executivo federal consiga a aprovação de sua agenda, incluindo emendas à Constituição referentes a matérias que modificam o status quo federativo.

Esse artigo buscou contribuir para a ampliação do conhecimento acerca da problemática central da política: a produção e a reprodução de bens públicos através de processos de negociação entre atores autointeressados, em contextos muitas vezes adversos. Contudo, há ainda um longo caminho pela frente.

Recebido para publicação em 21 de março de 2017 Aceito em 10 de julho de 2017

\section{REFERÊNCIAS}

ABRANCHES, S. H. O presidencialismo de coalizão: o dilema institucional brasileiro. Dados, Rio de Janeiro, v. 31, n. 1, p. 5-33, 1988.

ABRUCIO, F. L. A Coordenação Federativa no Brasil: A 
Experiência do Período FHC e os Desafios do Governo Lula. Revista de Sociologia e Política, Curitiba, n. 24, p. 41-67, jun. 2005.

Os Barões da Federação: os governadores e a redemocratização brasileira. São Paulo: Hucitec, 1998.

AMORIM NETO, O.; SANTOS, F. O segredo Ineficiente revisto: o que propõem e o que aprovam os deputados brasileiros. Dados, Rio de Janeiro, v. 46, n. 4, p. 661-698, 2003

ARRETCHE, M. Continuidades e descontinuidades da Federação Brasileira: de como 1988 facilitou 1995. Dados, Rio de Janeiro, v. 52, n. 2, p. 377-423, 2009.

The veto power of subnational governments in Brazil: political institutions and parliamentary behavior in the post-1988 Period. Brazilian Political Sciences Review, Rio de Janeiro, v.1, n. 2, p. p. 40-73, 2007.

Federalismo e Políticas Sociais no Brasil. Problemas de Coordenação e Autonomia. São Paulo em Perspectiva, São Paulo, v. 18, n. 2, p. 17-26, 2004.

; RODDEN, J. Política Distributiva na Federação: estratégias eleitorais, barganhas legislativas e coalizões de governo. Dados, Rio de Janeiro, v. 47, n. 3, p. 549-76, 2004.

BORGES, A. Nacionalização Partidária e Estratégias Eleitorais no Presidencialismo de Coalizão. Dados, Rio de Janeiro, v. 58, n. 3, p. 651-688, 2015.

Rethinking State Politics: The Withering of State

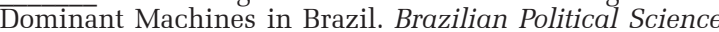
Review, São Paulo, v. 1, n. 2, p. 108-136, 2007.

CALVO, E.; ESCOLAR, M. La nueva política de partidos en la Argentina: crisis política, realineamientos partidarios y reforma electoral. Buenos Aires: Prometeo, 2005.

CALVO, E. et al. Las Fuentes Institucionales del gobierno dividido en la Argentina: sesgo mayoritario, sesgo partidario y competencia electoral en las legislaturas provinciales argentinas. In: CALVO, E.; MEDINA, J. M. A. (Ed.). El Federalismo Electoral Argentino: Sobre representación, Reforma Política y Gobierno Dividido en la Argentina. Buenos Aires: EUDEBA, 2001. p. 53-98.

CHEIBUB, J. A. FIGUEIREDO, A.; LIMONGI, F. Partidos Políticos e Governadores como Determinantes do Comportamento Legislativo na Câmara dos Deputados, 1988-2006. Dados, Rio de Janeiro, v. 52, n. 2, p. 195-231, 2009.

CHHIBBER, K.; KOLLMAN, K. The Formation of National Party Systems: Federalism and Party Competition in Canada, Great Britain, India, and the United States. Princeton University Press, 2004.

EATON, K. Menem and the Governors: Intergovernamental Relations in the 1990s. In: LEVINSKY, S.; MURILLO, M. V. (Ed.) The Politics of Institutional Weakness Argentine Democracy. Pennsylvania State University Press, 2005. p.88-114.

FALLETI, T. A Sequential Theory of Decentralization: Latin American Cases in Comparative Perspective. American Political Science Review, Baltimore, v. 99, n. 3, p. 327-346, 2005.

FIGUEIREDO, A.; LIMONGI, F. Processo orçamentário e comportamento Legislativo: emendas individuais, apoio ao Executivo e programas de governo. Dados, Rio de Janeiro, v. 48, n. 4, p. 737-76, 2005.

Constitucional Change, Legislative Performance and Institucional Consolidation. Brazilian Review of Social Sciences, São Paulo, n. 1, p. 2000. Special Issue.

Executivo e Legislativo na Nova Ordem Institucional. Rio de Janeiro: FGV; São Paulo: Fapesp, 1999

O Congresso e as Medidas Provisórias: abdicação ou delegacão? Novos Estudos CEBRAP, São Paulo, n. 47, p. $127-54,1997$.
Partidos Políticos na Câmara dos deputados: 1989-1994. Dados, Rio de Janeiro, v. 38, n. 3, p. 479-525, 1995.

FIGUEIREDO, M. O eleitor a Preferência e o voto. Revista Insight Inteligência, Rio de Janeiro, jul./set. 2005.

GIBSON, E. L.; CALVO, E. Federalism and low-maintenance constituencies: Territorial dimensions of economic reform in Argentina. Studies in Comparative International Development, v. 35, n. 3, p. 32-55, 2000.

GIBSON, E.; CALVO, E. F.; FALLETI, T. G. Federalismo Realocativo: Sobre-representação Legislativa e Gastos Públicos no Hemisferio Ocidental. Opinião Pública, Campinas, v. 9, n. 1, 2003.

GORDIN, J. Patronage-Preserving federalism? Legislative malapportionment and subnational fiscal policies. GIGA, Hamburgo, n. 52, p. 1-18, June 2007.

JONES, M.; HWANG W: MICOZZI, J. P. Government and Opposition in the Argentine Congress, 1989-2007: Understanding InterParty Dynamics Through Roll Call Vote Analysis. Journal of Politics in Latin America, v. 1, n. 1, p. 67-96, 2009

; MAINWARING, S. The Nationalization of Parties and Party Systems: An Empirical Measure and an Application to the Americas. Notre Dame: University of Notre Dame Press, 2003. (Working Paper, n. 304).

MAHONEY, J. SCHENSUL, D. Historical Context and Path Dependence. In: GOODIN, R. E.; TILLY, C. (Ed.). The Oxford Handbook of Contextual Analysis. Oxford: Oxford University Press, 2011. p. 454-471.

MELO, C. R. Eleições Presidenciais, Jogos Aninhados e Sistema Partidário no Brasil. Revista Brasileira de Ciência Política, Brasília, DF, n. 4, p. 13-41, 2010.

MELO, Marcus André. O sucesso inesperado das reformas de segunda geração: federalismo, reformas constitucionais e política social. Dados, Rio de Janeiro, v. 48, n. 4, dec. 2005

MORA, M. Federalismo e dívida estadual no Brasil. Rio de Janeiro: Ipea, 2002. (Texto para Discussão, n. 866).

MUSTAPIC, A. M. Oficialistas y Diputados: las relaciones Ejecutivo-Legislativo en la Argentina. Desarrollo Económico, Buenos Aires, v. 39, n. 156, p. 571-595, 2000.

NORTH, D. C. Institutions, Institutional Change, and Economic Performance. New York: Cambridge University Press, 1990

.; WEINGAST, B. Constitutions and Commitment: Evolution of Institutions Governing Public Choice. The Journal of Economic History, p. 803-832, v. 49, n. 4, 1989.

NUNES, E. A gramática política no Brasil: clientelismo e insulamento burocrático. Rio de Janeiro: Zahar Editores, 1997

REGIS, A. O Novo Federalismo Brasileiro. Rio de Janeiro: Editora Forense, 2009

RIKER, W. Federalism. In: GREENSTEIN, F; POLSBY; N. W. (Ed.). Handbook of Political Science. Reading: AddisonWesley Pub. Co., 1975. v. 5, p. 93-172.

The nature of trust. In: TADESHI, J. (Ed.). Perspectives on social power. Chicago: Aldine, 1974. p. 6381.

Federalism: Origin, Operation, Significance.

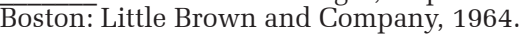

Theory of Political Coalitions. New Haven: Yale University Press, 1962.

RODRÍGUEZ, J.; BONVECCHI, A. El papel del Poder Legislativo en el proceso Presupuestario Argentino (19842004). Desarrollo Económico, Buenos Aires, v. 45, n. 180 , 
p.enero-marzo 2006.

SANTOS, F. Parties and Committees in the Coalition Presidential System. Dados, Rio de Janeiro, p. 237-64.v. 45, n. 2, 2002 .

SANTOS, W. G. dos. (Org.). Votos e partidos: almanaque de dados eleitorais: Brasil e Outros Países. Rio de Janeiro: FGV, 2002.

SCHARPF, Fritz. The Joint-Decision Trap: Lessons from German Federalism and European Integration. Public Administration, [S.l.], v. 66, n. 3, p. 239-278, 1988.

SIMPSON, X. Dinâmicas intergovernamentais comparadas: Brasil e Argentina em Foco. [S.l.]: Novas Edições Acadêmicas, 2015.

Dinâmicas federalistas no Brasil e Argentina:

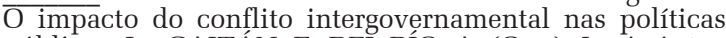
públicas. In: GAITÁN, F.; DEL RÍO, A. (Org.). Instituições, Política e Desenvolvimento: América Latina frente ao século XXI. Curitiba: Editora CVR, 2013. v. 1. p. 109-136.
STASAVAGE, D. Credible Commitment in Early Modern Europe: North and Weingast Revisited. Journal of Law, Economics, and Organization, Oxford, v. 18, n. 1, p. 155186, 2002.

STEPAN, A. Para uma Nova Análise Comparativa do Federalismo e da Democracia: Federações que Restringem ou Ampliam o Poder do Demos. Dados, Rio de Janeiro, v. 42, n. 2, 1999. P. 197-251.

TSEBELIS, G. Processo decisório em sistemas políticos: veto players no presidencialismo, parlamentarismo, multicameralismo e pluripartidarismo. Revista Brasileira de Ciências Sociais, São Paulo, v. 12, n. 34, p. 89-117, 1997.

WEINGAST, B. R. The Economic Role of Political Institutions: Market-Preserving Federalismand Economic Development. Journal of Law, Economics and Organization, New, New Haven, v. 11, n. 1, p. 1-31, 1995.

WIBBELS, E. Federalism and the Market: Intergovernmental Conflict and Economic Reform in the Developing World. New York: Cambridge University Press, 2005. 
THE FEDERAL SENSE: the relation between party systems and public policies in Brazil and Argentina

\section{Ximena Simpson}

This study highlights the role of the party systems in Brazil and Argentina as a central element for understanding the capacity of coordination of intergovernmental relations (IGRs) and, consequently, for the implementation of national public policies. The main argument is that the levels of conflict of IGRs, throughout history, are modeled by the party system, and it has direct implications in the public policies. The hypothesis is that a greater nationalization of the party system results in more cooperative IGRs, and, consequently, in a greater capacity of territorial penetration of the central state, with intertemporal public policies. It is concluded that the IGRs dynamics in such countries achieve opposite results: while in Argentina it seems to encourage a greater party territorialization, in Brazil it aims at build a more cooperative interaction framework.

KeYwords: Federalism. Party System. Public policies. Brazil. Argentina.
LE LIEN FEDERAL: la relation entre les systèmes des partis et les politiques publiques au Brésil et en Argentine

\section{Ximena Simpson}

Cette recherche met en évidence le rôle du système des partis au Brésil et en Argentine en tant qu'élément central pour comprendre la capacité de coordination des relations intergouvernementales (RIGs) et, par conséquent, pour la mise en œuvre des politiques publiques nationales. L'argument central est que les niveaux de conflit des RIGs, tout au long de l'histoire, sont influencés par le système de parti, avec des implications directes dans les politiques publiques. L'hypothèse est qu'une plus ample nationalisation du système de parti entraîne des RIGs plus coopératifs et, par conséquent, une plus grande capacité de pénétration territoriale de l'État central avec des politiques publiques inter temporelles. On en arrive à la conclusion que, dans les pays pris en considération, la dynamique des RIGs, atteint des résultats opposés. Alors qu'en Argentine elle semble favoriser une plus grande territorialisation des partis, au Brésil elle va vers la construction d'un cadre d'interaction plus coopératif.

Mots-CLÉs: Fédéralisme. Système des partis. Politiques publiques. Brésil. Argentine.

Ximena Simpson - Doutora em Ciência Política. Professora e pesquisadora Escola de Política e Governo da Universidade Nacional de General San Martín (UNSAM), Argentina. Especialista em política comparada latino-americanacom destaque para os casos de Brasil e Argentina. Dirige a rede de pesquisa sobre "Capacidades Estatais em Estados multinível. Uma análise da relação entre a dinâmica política e burocracia no Brasil e na Argentina”, composta por pesquisadores de universidades brasileiras, argentinas e norte-americanas. Publicações recentes: Entre la autonomía y la coordinación. Aportes teóricos al análisis de las políticas de cooperación descentralizada en Brasil y en Argentina. Revista de Estudios Políticos y Estratégicos, v. 5, n 1, UTEM- Chile, Primer semestre de 2017; Dinâmicas intergovernamentais comparadas. Brasil e Argentina em foco. Novas Edições Acadêmicas. 2015; Dinâmicas federalistas no Brasil e Argentina. O impacto do conflito intergovernamental nas políticas públicas. In: GAITÁN, Flavio; DEL RÍO, Andrés. (Org.) Instituições, Política e Desenvolvimento. América Latina frente ao século XXI. 1. ed. Curitiba: CVR Editora, 2013. v. 1. 402p. 
